\title{
Consultation Patterns of Neurosurgical Patients Admitted to Intensive Care Units Vary with Neurointensivist Co-management
}

\author{
Hyunjun $\mathrm{Cho}^{1}$, Yun Im Lee ${ }^{2}$, Jeong-Am Ryu ${ }^{1,2}$ \\ ${ }^{1}$ Department of Neurosurgery, Samsung Medical Center, Sungkyunkwan University School of Medicine, Seoul, Korea \\ ${ }^{2}$ Department of Critical Care Medicine, Samsung Medical Center, Sungkyunkwan University School of Medicine, Seoul, Korea
}

Received: September 25, 2020

Accepted: October 6, 2020

\section{Corresponding Author:}

Jeong-Am Ryu, M.D., Ph.D.

Department of Critical Care Medicine and Department of Neurosurgery, Samsung Medical Center, Sungkyunkwan University School of Medicine, 81 Irwon-ro, Gangnam-gu, Seoul 06351, Korea Tel: +82-2-3410-6399

Fax: +82-2-2148-7088

E-mail: lamyud.ryu@samsung.com

\section{Objective}

To evaluate the consultation patterns in the neurosurgical intensive care unit (ICU) and the neurointensivist factors that may influence consultations.

\section{Methods}

This was a retrospective, single-center, observational study of neurosurgical patients admitted to ICU from January 2013 to December 2019. In this study, only formal consultation was defined as the consultation, but curbside consultation was excluded.

Results

A total of 12,743 patients were analyzed in this study. Malignancy (54.6\%) and hypertension (30.6\%) were the most common comorbidities. Brain tumor (43.0\%) and microvascular decompression $(17.6 \%)$ were the most common reasons for ICU admission. Among total neurosurgical patients, 3,056 (24.0\%) patients had 8,789 consultations during their ICU stay. The departments of Infectious disease (27.9\%), Pediatrics (9.6\%) and Rehabilitation (9.6\%) were the three most frequently consulted specialties, accounting for up to $47.1 \%$ of all the consultations. The frequency of the consultations involving infectious disease and pediatric services except for permission to use restricted antibiotics, and consultation services involving neurology, pulmonology and respiratory care by respiratory therapists were reduced compared to levels before neurointensivist co-management. However, the consultations with otorhinolaryngologists, radiologists and endocrinologists were increased compared to levels after neurointensivist co-management. Consultations replied within $24 \mathrm{~h}$ before initiation of neurointensivist co-management were increased.

Conclusion

In this study, we were able to identify an interesting consultation patterns of neurosurgical and neurocritically ill patients. Neurointensivist co-management may have an impact on the consultation under general and neurocritical management.

Keywords: Referral and consultation; Neurosurgery; Intensive care units 


\section{INTRODUCTION}

Neurosurgical and neurocritically ill patients admitted to the intensive care unit (ICU) may have other medical and surgical problems as well as neurosurgical issues ${ }^{16)}$. Neurocritically ill patients and old neurosurgical patients often exhibit various comorbidities $^{2,5,10)}$. Therefore, they may frequently manifest various ailments during their ICU stay. The timely evaluation of heart diseases and airway or pulmonary complaints is critical ${ }^{2,5,10}$. Therefore, consultation with different medical and surgical subspecialists is an important strategy to manage the care of these patients. However, there is limited data regarding the consultation patterns of neurosurgical patients in the ICU.

Neurointensivists are specialists equipped with skills and expertise to manage various aspects of neurosurgical and neurocritically ill patients admitted to the ICU. They focus on the management of patients with acute neurological conditions including traumatic brain injury, stroke, status epilepticus, and neuromuscular respiratory failure as well as general critical care ${ }^{1,3,16,17)}$. Therefore, neurointensivist co-management may affect the consultation patterns of these patients.

We conducted a retrospective observational study of neurosurgical and neurocritically ill patients who were admitted to the ICU. The objective of this study was to evaluate the consultation patterns in the neurosurgical ICU and identify the neurointensivist factors that may influence the consultations of these patients under the care of general and neurocritical managements.

\section{MATERIALS AND METHODS}

\section{Study population and design}

This was a retrospective, single-center, observational study of neurosurgical patients admitted to the ICU at Samsung Medical Center from January 2013 to December 2019. This study was approved by the Institutional Review Board of Samsung Medical Center (approval number: SMC 2020-09-082). The requirement for informed consent was waived due to its retrospective nature. We included neurosurgical patients admitted to the ICU during the study period. We excluded patients who had insufficient medical records.

\section{Definitions and outcomes}

All consecutive neurosurgical and neurocritically ill patients admitted to the ICU were evaluated in this study. The following data were extracted from Clinical Data Warehouse on ICU admission: age, sex, comorbidity, severity score, and reasons for ICU admission. Data regarding consultations of neurosurgical patients were also obtained through the Clinical Data Warehouse. The initial Glasgow Coma Scale (GCS) was defined as the best GCS within $24 \mathrm{~h}$ of ICU admission. The severity of illness was assessed by the Acute Physiology and Chronic Health Evaluation II (APACHE II) scores ${ }^{9}$. In this study, only formal consultation was defined as the consultation, whereas curbside consultation was excluded ${ }^{4)}$.

Neurointensivist co-management was initiated on October 1, $2014^{16)}$. During the co-management period, the neurointensivist worked for 6 days per week during the daytime. The neurointensivist was involved in various aspects of care, such as general critical care, neurocritical care and post-operative management, including hemodynamic monitoring, nutritional support, and use of mechanical ventilation and renal replacement therapy, neuro-monitoring, and control of malignant intracranial hypertension ${ }^{16}$. The neurocritical care team consisted of an attending neurointensivist, neurosurgical resident, critical care dietitian and pharmacist ${ }^{16}$.

We evaluated the overall consultation patterns of the neurosurgical patients in the ICU and compared the consultation patterns before and after initiation of mandatory neurointensivist co-management.

\section{Statistical analyses}

Our center has constructed the "Clinical Data Warehouse Darwin-C" designed for investigators to search and retrieve de-identified medical records from the electronic archive system. After finalizing the patient list for this study, the clinical data and laboratory data were extracted from the Clinical Data Warehouse Darwin-C. All data are presented as means \pm standard deviations for continuous variables and numbers (percentages) for categorical variables. Data were compared using Student's t-test for continuous variables and the chi-square test or Fisher's exact test for categorical variables. All tests were two-sided and $p$ values of less than 0.05 were considered statistically significant. All data were analyzed using $\mathrm{R}$ Statistical Software (version 4.0.2; R Foundation for Statistical Computing, Vienna, Austria).

\section{RESULTS}

\section{Baseline characteristics}

A total of 12,743 patients were analyzed. Among these patients, a quarter of patients $(3,353)$ were admitted to an ICU other than the neurosurgery ICU. The mean age of all patients was $48.8 \pm$ 19.8 years. The study included 5,630 (44.2\%) male patients. Malignancy $(54.6 \%)$ and hypertension (30.6\%) were the most common comorbidities. Brain tumors (43.0\%) and microvascular decompressions $(17.6 \%)$ were the most common reasons for ICU admission. GCS and APACHE II scores on ICU admission were 
higher in patients compared with levels before initiation of neurointensivist co-management (both $\mathrm{p}<0.001$ ) (Table 1 ).

\section{Consultations patterns before and after neurointensivist co-management}

Among 12,743 neurosurgical patients, 3,056 (24.0\%) had 8,789 consultations during their ICU stay. Half of all the consulted patients $(1,337)$ needed two and more consultations (Table 2).
Among the departments consulted, Infectious diseases (27.9\%), Pediatrics (9.6\%) and Rehabilitation (9.6\%) were the three most frequently consulted specialties (Fig. 1). These services constituted $47.1 \%$ of the total consultations. Routine and emergent consultations $(64.4 \%)$ and permission to use restricted antibiotics (21.5\%) were the most common types of consultations. Half of all the emergent consultations were determined by a surgeon.

The routine and emergent consultations with Infectious disease

Table 1. Demographics and clinical factor of patients in neurointensive care unit who had elevated pancreatic enzymes

\begin{tabular}{|c|c|c|c|c|}
\hline & Before $(\mathrm{N}=3,457)$ & After $(\mathrm{N}=9,286)$ & Total $(\mathrm{N}=12,743)$ & p-value \\
\hline Age $(y r)-$ mean $\pm S D$ & $47.6 \pm 20.4$ & $49.3 \pm 19.5$ & $48.8 \pm 19.8$ & $<0.001$ \\
\hline Gender, male - no. of patients (\%) & $1,579(45.7)$ & $4,051(43.6)$ & $5,630(44.2)$ & 0.04 \\
\hline \multicolumn{5}{|l|}{ Comorbidities — no. of patients (\%) } \\
\hline Malignancy & $1,844(53.3)$ & $5,108(55.0)$ & $6,952(54.6)$ & 0.097 \\
\hline Hypertension & $972(28.1)$ & $2,927(31.5)$ & $3,899(30.6)$ & $<0.001$ \\
\hline Dyslipidemia & $572(16.5)$ & $1,745(18.8)$ & $2,317(18.2)$ & 0.004 \\
\hline Diabetes mellitus & $475(13.7)$ & $1309(14.1)$ & $1784(14.0)$ & 0.627 \\
\hline Chronic kidney disease & $104(3.0)$ & $252(2.7)$ & $356(2.8)$ & 0.403 \\
\hline Chronic liver disease & $65(1.9)$ & $155(1.7)$ & $220(1.7)$ & 0.461 \\
\hline Cardiovascular disease & $61(1.8)$ & $159(1.7)$ & $220(1.7)$ & 0.901 \\
\hline Cause of ICU admission — no. of patients (\%) & & & & $<0.001$ \\
\hline Brain tumor & $1,402(40.6)$ & $4,081(43.9)$ & $5,483(43.0)$ & \\
\hline Microvascular decompression & $575(16.6)$ & $1,664(17.9)$ & $2,239(17.6)$ & \\
\hline Elective vascular surgery & $522(15.1)$ & $1,464(15.8)$ & $1,986(15.6)$ & \\
\hline Intracranial hemorrhage & $177(5.1)$ & $380(4.1)$ & $557(4.4)$ & \\
\hline Traumatic brain injury & $175(5.1)$ & $339(3.7)$ & $514(4.0)$ & \\
\hline Subarachnoid hemorrhage & $132(3.8)$ & $332(3.6)$ & $464(3.6)$ & \\
\hline Spinal surgery & $114(3.3)$ & $236(2.5)$ & $350(2.7)$ & \\
\hline Congenital anomaly & $38(1.1)$ & $108(1.2)$ & $146(1.1)$ & \\
\hline Central nerve system infection & $35(1.0)$ & $80(0.9)$ & $115(0.9)$ & \\
\hline Cerebral infarction & $34(1.0)$ & $39(0.4)$ & $73(0.6)$ & \\
\hline Others & $253(7.3)$ & $563(6.1)$ & $816(6.4)$ & \\
\hline Initially admitted ICU— no. of patients (\%) & & & & $<0.001$ \\
\hline Neurosurgical ICU & $2,317(67.0)$ & $7,073(76.2)$ & $9,390(73.7)$ & \\
\hline Other ICUs & $1,140(33.0)$ & $2,213(23.8)$ & $3,353(26.3)$ & \\
\hline GCS on ICU admission - mean \pm SD & $14.3 \pm 2.2$ & $14.7 \pm 1.5$ & $14.6 \pm 1.7$ & $<0.001$ \\
\hline APACHE II score on ICU admission - mean \pm SD & $4.3 \pm 5.2$ & $3.3 \pm 4.4$ & $3.6 \pm 4.6$ & $<0.001$ \\
\hline
\end{tabular}

ICU: intensive care unit; SD: standard deviation; GCS: Glasgow Coma Scale; APACHE: Acute Physiology and Chronic Health Evaluation.

Table 2. Demographics and clinical factor of patients in neurointensive care unit who had elevated pancreatic enzymes

\begin{tabular}{lccc}
\hline & Before $(\mathrm{N}=3,457)$ & After $(\mathrm{N}=9,286)$ & Total $(\mathrm{N}=12,743)$ \\
\hline $\begin{array}{l}\text { Number of consultation - no. of patients }(\%) \\
0\end{array}$ & $2,557(74.0)$ & $7,130(76.8)$ & $9,687(76.0)$ \\
1 & $472(13.7)$ & $1,207(13.0)$ & $1,679(13.2)$ \\
2 & $158(4.6)$ & $391(4.2)$ & $549(4.3)$ \\
3 & $83(2.4)$ & $170(1.8)$ & $253(2.0)$ \\
4 & $45(1.3)$ & $110(1.2)$ & $155(1.2)$ \\
5 and more & $142(4.1)$ & $278(3.0)$ & $420(3.3)$ \\
\hline
\end{tabular}




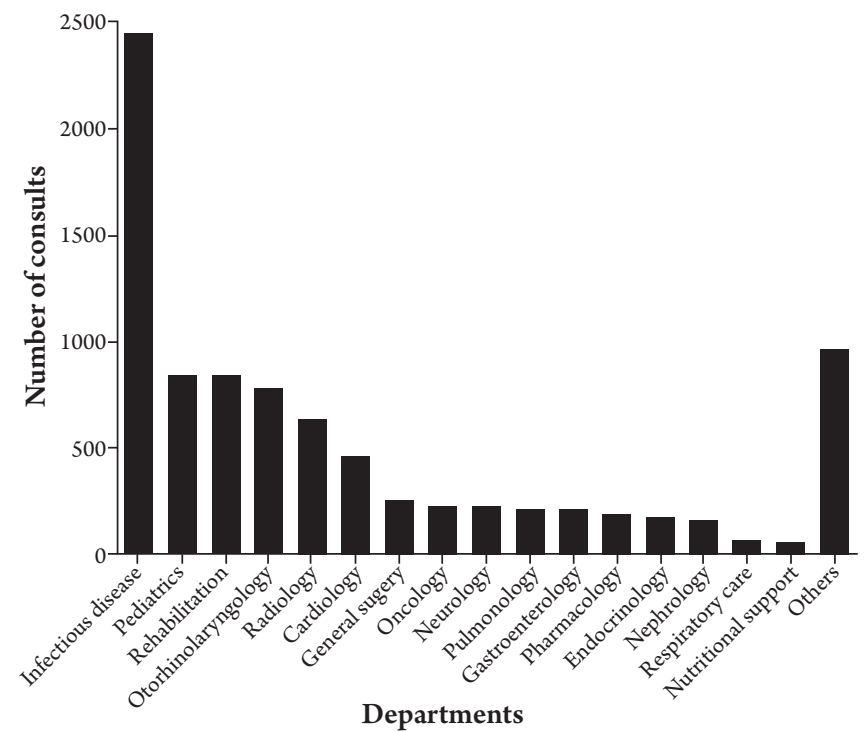

Fig. 1. Distribution of consultations among neurosurgical patients admitted to intensive care unit.

and Pediatrics specialists except permission to use restricted antibiotics, and those involving Neurology, Pulmonology and Respiratory Care by a respiratory therapist were significantly decreased compared to the levels before neurointensivist co-management. However, the consultations with Otorhinolaryngology, Radiology and Endocrinology departments were increased compared to the levels after initiation of neurointensivist co-management. The consultations replied within $24 \mathrm{~h}$ were also increased after compared to the levels before initiation of neurointensivist co-management (Table 3).

\section{DISCUSSION}

In this study, we investigated the consultation patterns and the neurointensivist factors that may influence the consultations of neurosurgical and neurocritically ill patients under the care of general and neurocritical managements. The major findings are as follows. First, a quarter of patients admitted to the ICUs needed consultations for medical or other surgical supports, and a half of them needed two or more consultations. Second, Infectious disease, Pediatrics and Rehabilitation were the three most frequently consulted specialty services. Third, consultations with Infectious disease and Pediatrics experts except for permission to use restricted antibiotics and those involving Neurology, Pulmonology and Respiratory Care services by respiratory therapist were significantly decreased compared to the levels before initiation of neurointensivist co-management. Fourth, the frequency of the consultations replied within $24 \mathrm{~h}$ increased compared to the level before initiation of neurointensivist co-management.

Neurosurgical and neurocritically ill patients carry various co- morbidities and complications during their ICU stay ${ }^{6,7,12,15)}$. Cardiopulmonary complications are particularly common in elderly neurosurgical patients and neurocritically ill patients ${ }^{6,15,16}$. In addition, postoperative infectious complications are not uncommon ${ }^{6,13)}$. It may be difficult to manage pediatric patients unless a pediatrician is available. Therefore, consultations with medical and other surgical subspecialties play an important role in patient's treatment. Recently, early rehabilitation has been emphasized in neurosurgical $\mathrm{ICU}^{14)}$. Early mobilization of critically ill patients has been shown to reduce the complications associated with critical illness ${ }^{8,11)}$. Therefore, based on comorbidities, complications and rehabilitative treatment trends, Infectious disease, Pediatrics and Rehabilitation experts might be the three most frequently consulted professionals by neurosurgical patients in this study.

Neurointensivists are critical care physicians specifically focused on the management of neurocritically ill patients ${ }^{1,3,16,17)}$. Because of this increasing complexity of acute care involving the neurocritically ill patients, a multidisciplinary approach to neurocritical care is necessary ${ }^{16)}$. The frequency of infectious, pediatric and respiratory consultations was reduced after neurointensivist co-management, which may be related to general critical care by neurointensivist. However, the frequency of cardiologist consultation was not significantly different between before and after neurointensivist co-management. Following prior assessment by neurointensivist, a cardiologist consultation was performed to confirm acute coronary syndrome in this study. The increase in Otorhinolaryngology consultation was due to an increase in endoscopic pituitary surgery. The response period for the consultation was shortened compared to the response before initiation of neurointensivist co-management, which may be because the neurointensivist requested prompt responses from a specialist in cases of emergent consultation.

This study has several limitations. First, it was a retrospective review of medical records and the data extracted from Clinical Data Warehouse. Second, most requests for consultation were determined by neurosurgeon. It was not protocol-based. Therefore, the non-randomized nature of registry data might have resulted in selection bias. Third, the distribution of neurosurgical diseases was different from that of the general neurosurgery ICU, and the proportion of patients with brain tumors was particularly high. Finally, the neurointensivist in this study is a neurologist trained to manage all aspects of critically ill patients in medical and surgical ICUs. The treatment approach of this neurointensivist might have influenced the consultation patterns of neurocritically ill patients ${ }^{16)}$.

\section{CONCLUSION}

In this study, we were able to identify an interesting consultation 
Table 3. Distribution of consultations before and after neurointensivist co-management

\begin{tabular}{|c|c|c|c|c|}
\hline & Before $(\mathrm{N}=2,963)$ & After $(\mathrm{N}=5,826)$ & Total $(\mathrm{N}=8,789)$ & p-value \\
\hline \multicolumn{5}{|l|}{ Consulted department — no. of patients (\%) } \\
\hline Infectious disease total & $840(28.3)$ & $1,615(27.7)$ & $2,455(27.9)$ & 0.551 \\
\hline Routine consultation & $326(11.0)$ & $457(7.8)$ & $783(8.9)$ & $<0.001$ \\
\hline Permission to use restricted antibiotic & $514(17.3)$ & $1,158(19.9)$ & $1,672(19.0)$ & 0.005 \\
\hline Pediatrics total & $316(10.7)$ & $528(9.1)$ & $844(9.6)$ & 0.018 \\
\hline Routine consultation & $236(8.0)$ & $386(6.6)$ & $622(7.1)$ & 0.023 \\
\hline Permission to use restricted antibiotic & $80(2.7)$ & $142(2.4)$ & $222(2.5)$ & 0.503 \\
\hline Rehabilitation & $302(10.2)$ & $541(9.3)$ & $843(9.6)$ & 0.185 \\
\hline Otorhinolaryngology & $201(6.8)$ & $583(10.0)$ & $784(8.9)$ & $<0.001$ \\
\hline Radiology & $181(6.1)$ & $455(7.8)$ & $636(7.2)$ & 0.004 \\
\hline Cardiology & $144(4.9)$ & $318(5.5)$ & $462(5.3)$ & 0.255 \\
\hline General surgery & $81(2.7)$ & $173(3.0)$ & $254(2.9)$ & 0.578 \\
\hline Oncology & $76(2.6)$ & $151(2.6)$ & $227(2.6)$ & 0.997 \\
\hline Neurology & $92(3.1)$ & $134(2.3)$ & $226(2.6)$ & 0.029 \\
\hline Pulmonology & $92(3.1)$ & $123(2.1)$ & $215(2.4)$ & 0.005 \\
\hline Gastroenterology & $73(2.5)$ & $141(2.4)$ & $214(2.4)$ & 0.959 \\
\hline Pharmacology & $55(1.9)$ & $132(2.3)$ & $187(2.1)$ & 0.238 \\
\hline Endocrinology & $41(1.4)$ & $138(2.4)$ & $179(2.0)$ & 0.003 \\
\hline Nephrology & $67(2.3)$ & $99(1.7)$ & $166(1.9)$ & 0.081 \\
\hline Respiratory care by respiratory therapist & $35(1.2)$ & $35(0.6)$ & $70(0.8)$ & 0.006 \\
\hline Nutritional support & $16(0.5)$ & $46(0.8)$ & $62(0.7)$ & 0.235 \\
\hline Others & $351(11.8)$ & $614(10.5)$ & $965(11.0)$ & 0.069 \\
\hline Type of consultation - no. of patients (\%) & & & & 0.001 \\
\hline Routine and emergent consultation & $1,996(67.4)$ & $3,661(62.8)$ & $5,657(64.4)$ & \\
\hline Permission to use restricted antibiotic & $594(20.0)$ & $1,300(22.3)$ & $1,894(21.5)$ & \\
\hline Request for examination & $302(10.2)$ & $687(11.8)$ & $989(11.3)$ & \\
\hline Pill identification & $55(1.9)$ & $132(2.3)$ & $187(2.1)$ & \\
\hline Nutrition support & $16(0.5)$ & $46(0.8)$ & $62(0.7)$ & \\
\hline Consultation replied within $24 \mathrm{~h}$ - no. of patients (\%) & $1,476(49.8)$ & $3,838(65.9)$ & $5,314(60.5)$ & $<0.001$ \\
\hline Emergent consultation — no. of patients (\%) & $218(7.4)$ & $471(8.1)$ & $689(7.8)$ & 0.247 \\
\hline Reasons of emergent consultation - no. of patients (\%) & & & & 0.556 \\
\hline Judgement of surgeon & $124(57.4)$ & $264(55.3)$ & $388(56.0)$ & \\
\hline Acute deterioration of disease & $53(24.5)$ & $114(23.9)$ & $167(24.1)$ & \\
\hline Instability of patients' vital signs & $17(7.9)$ & $52(10.9)$ & $69(10.0)$ & \\
\hline For emergent operation & $22(10.2)$ & $44(9.2)$ & $66(9.5)$ & \\
\hline Others & $0(0)$ & $3(0.6)$ & $3(0.4)$ & \\
\hline
\end{tabular}

patterns of neurosurgical and neurocritically ill patients. Neurointensivist co-management may affect the consultation patterns of these patients under the care of general and neurocritical management.

\section{NOTES}

\section{Conflict of interest}

No potential conflict of interest relevant to this article was reported.

\section{Informed Consent}

The requirement for informed consent was waived due to its retrospective nature in this study.

\section{Acknowledgements}

We would like to thank Hye Jung Kim, nursing director of the neurosurgical intensive care unit, for providing excellent advice and engaging in fruitful discussions. We would also like to thank all nurses of the neurosurgery intensive care unit at Samsung Medical Center. 


\section{REFERENCES}

1. Adrian A, Jarquin-Valdivia DCB J. Claude Hemphill III: The Role of the Neurointensivist. Seminars in Neurosurgery 2003; 14:131-138.

2. Ay H, Furie KL, Singhal A, Smith WS, Sorensen AG, Koroshetz WJ. An evidence-based causative classification system for acute ischemic stroke. Ann Neurol 2005;58:688-697.

3. Bithal P. Neurointensive Care Unit and neurointensivist: Do we need them? J Neuroanaesth Crit Care 2016;3:1.

4. Burden M, Sarcone E, Keniston A, Statland B, Taub JA, Allyn $\mathrm{RL}$, et al. Prospective comparison of curbside versus formal consultations. J Hosp Med 2013;8:31-35.

5. Chen Z, Venkat P, Seyfried D, Chopp M, Yan T, Chen J. BrainHeart Interaction: Cardiac Complications After Stroke. Circulation research 2017;121:451-468.

6. De la Garza-Ramos R, Kerezoudis P, Tamargo RJ, Brem H, Huang J, Bydon M. Surgical complications following malignant brain tumor surgery: an analysis of 2002-2011 data. Clin Neurol Neurosurg 2016;140:6-10.

7. Hammer A, Steiner A, Ranaie G, Yakubov E, Erbguth F, Hammer CM, et al. Impact of Comorbidities and Smoking on the Outcome in Aneurysmal Subarachnoid Hemorrhage. Sci Rep 2018;8:12335-12335.

8. Kayambu G, Boots R, Paratz J. Physical therapy for the critically ill in the ICU: a systematic review and meta-analysis. Crit Care Med 2013;41:1543-1554.

9. Kumpers P, Hafer C, Lukasz A, Lichtinghagen R, Brand K, Flis- er D, et al. Serum neutrophil gelatinase-associated lipocalin at inception of renal replacement therapy predicts survival in critically ill patients with acute kidney injury. Crit Care 2010;14:R9.

10. Lee K, Rincon F. Pulmonary complications in patients with severe brain injury. Crit Care Res Pract 2012;2012:207247.

11. Li Z, Peng X, Zhu B, Zhang Y, Xi X. Active mobilization for mechanically ventilated patients: a systematic review. Arch Phys Med Rehabil 2013;94:551-561.

12. Lin CY, Chien CC, Chen HA, Su FM, Wang JJ, Wang CC, et al. The impact of comorbidity on survival after hemorrhagic stroke among dialysis patients: a nationwide population-based study. BMC Nephrol 2014;15:186.

13. McClelland S 3rd, Hall WA. Postoperative central nervous system infection: incidence and associated factors in 2111 neurosurgical procedures. Clin Infect Dis 2007;45:55-59.

14. Olkowski BF, Shah SO. Early Mobilization in the Neuro-ICU: How Far Can We Go? Neurocrit Care 2017;27:141-150.

15. Ostwald SK, Wasserman J, Davis S. Medications, comorbidities, and medical complications in stroke survivors: the CAReS study. Rehabil Nurs 2006;31:10-14.

16. Ryu JA, Yang JH, Chung CR, Suh GY, Hong SC. Impact of Neurointensivist Co-management on the Clinical Outcomes of Patients Admitted to a Neurosurgical Intensive Care Unit. J Korean Med Sci 2017;32:1024-1030.

17. Suarez JI. Outcome in neurocritical care: advances in monitoring and treatment and effect of a specialized neurocritical care team. Crit Care Med 2006;34:S232-238. 